\title{
Neuropsychological studies of callosal agenesis ${ }^{1}$
}

A developmental error or arrest during the foetal growth of the telencephalic midline can lead to partial or complete agenesis of the corpus callosum. A person who is born with no corpus callosum at all is likely also to lack the hippocampal commissure, but unlikely to lack the anterior commissure (Loeser \& Alvord, 1968a). Indeed, some congenitally acallosal individuals appear to have an enlarged anterior commissure (Bossy, 1970; Loeser \& Alvord, 1968 b). Their other commissures, as far as is known, do not differ appreciably from those of a normal brain. Against this background, behavioural investigations of totally acallosal subjects have been largely directed towards answering three neuropsychological questions. First, is an intact corpus callosum necessary for cerebral dominance to be established? Secondly, given that in most respects the 'disconnection syndrome' well known in patients who have undergone surgical section of the cerebral commissures (Sperry, 1974) is absent in cases of agenesis, how does the brain compensate for such a drastic structural deficiency? And, thirdly, what are the limits of compensation, both in regard to the cross-integration of sensory information and in relation to behavioural capacities which may depend in a less obvious way upon interhemispheric collaboration? In recent years some progress has been made towards answering all three of these questions, although complete answers are still not available.

The first question relates to the ontogeny of cerebral dominance. Some theorists (e.g. Kinsbourne \& Hiscock, 1977) have argued that dominance may essentially be wired-in at birth, and that there is no good evidence that the degree of functional asymmetry between the cerebral hemispheres grows with age. Others (Selnes, 1974; Moscovitch, 1977; Denenberg, 1981) have argued that, even if there is the seed of cerebral asymmetry present at birth, this can only develop into the normal adult pattern through an inhibitory callosal interaction, by which one side can dominate and suppress the other. In support of their argument such theorists cite what they take to be evidence of weak or even non-existent lateralization of cerebral function in the acallosal brain. In particular, they cite small behavioural asymmetries in three types of test: tachistoscopic recognition (of words, letters and pictures), tactual naming of objects, and dichotic listening (to digits, syllables or words). It is true that following surgical callosal section in adulthood, even when the anterior commissure is spared, extreme asymmetries in these tasks are found (Sperry, 1974; McKeever et al. 1981). ${ }^{2}$ However, the fact that congenital absence of the callosum does not have these consequences could be fully explained by the compensatory development of other commissures, decussations, and/or ipsilateral sensory projections. Such re-wirings might easily co-exist with normal degrees of cerebral lateralization in callosal agenesis (Milner \& Jeeves, 1979, 1981). That some such development of neural pathways must have occurred is demonstrated by the existence of visual and tactile cross-matching abilities in acallosal subjects which are not present in patients with callosal section. These abilities (e.g. Ettlinger et al. 1972) cannot be explained by incomplete cerebral lateralization.

The question as to whether acallosal brains are incompletely lateralized cannot therefore be answered by comparing acallosal with callosotomized patients and demonstrating smaller behavioural asymmetries. On the other hand, it can be demonstrated that some asymmetry of function is present in acallosal brains. For example, there generally seems to be better tachistoscopic recognition of verbal and pictorial items presented in the right visual field which projects to the left hemisphere (Ettlinger et al. 1972; Jeeves et al. 1983). Furthermore, vocal responses to a photic stimulus have

1 Address for correspondence: Dr David Milner, Psychological Laboratory, University of St Andrews, St Andrews, Fife KY16 $9 J U$.

2 The reported exceptions are the anterior-commissure-spared patients D.S., S.P. and D.H. (Risse et al. 1978) and the completely sectioned patient L.B. (Sperry, 1974). Of these, the first has long-standing left-hemisphere damage and also may not have a total callosal section (Wilson et al. 1982) and the last three were operated upon at the ages 13,15 and 13 respectively. 
been found to be consistently faster (by about $17 \mathrm{~ms}$ ) in the right than in the left visual field in the acallosal K. C. (Milner, 1982). Although the evidence from dichotic listening studies (Chiarello, 1980; Jeeves et al. 1983) is less clear, it is compatible with a normal degree of cerebral dominance along with a non-suppressed left ear-left hemisphere ipsilateral projection (Chiarello, 1980; Milner \& Jeeves, 1979). It is further worth pointing out that, despite claims to the contrary, acallosal patients are usually right-handed (Chiarello, 1980; Milner \& Jeeves, 1979), so that asymmetry of motor control can certainly develop without a corpus callosum. (There is a slightly increased incidence of non-right handedness, but that is typical of neurological populations.) Finally, there have been two references in the literature to direct speech lateralization tests using the sodium amytal test, and one reported exclusive left-hemisphere control (Gazzaniga, 1970, p. 138, citing a personal communication from B. Milner). The other (on the left-handed patient S.K.) reported apparently bilateral control of speech (Gott \& Saul, 1978); however, about 15\% of left-handed people with intact commissures also apparently possess such dual control (Rasmussen \& Milner, 1977).

Perhaps the most prudent conclusion would be that there may be greater differences in brain lateralization among acallosal individuals than among normal people. But there only needs to be one clear case of unilateral speech control for the question 'Is a corpus callosum necessary for cerebral dominance to be established?' to be answered in the negative. If the case of B. Milner (above) can be taken as one such example, then that is the end of the matter.

Nonetheless, the quest for bilateral control of speech in acallosals has yielded some intriguing information, by the use of a simple test in which subjects are shown tachistoscopically a word which spans the point of visual fixation. Sperry (1968) reported that the above-mentioned patient S.K., unlike the commissurotomized patients (Gazzaniga et al. 1965), could read such words completely and unhesitatingly. Yet if she were separately using both the left- and right-hemisphere speech mechanisms that she evidently possesses, some pronunciation errors would be expected in reading even such simple words as BEEN as against BEST. It seems instead that only one hemisphere is formulating and producing the spoken word. Perhaps the anterior commissure, for which there is radiological evidence in this patient (Gott \& Saul, 1978), is providing the speaking hemisphere with the complete visual information, and the weaker speech mechanism is being consistently over-ridden. In contrast, the acallosal B.F. (Jeeves et al. 1983), who would seem on tachistoscopic and dichotic evidence to have a reliable and normal functional lateralization, has been found to read words presented across the point of fixation with less fluency than words presented to the left or right. His performance with central presentation is characterized by hesitations and letter-by-letter reading, providing behavioural evidence for two separate and simultaneously functioning speech control mechanisms (Jeeves et al. 1983). The acallosal K. C. (Reynolds \& Jeeves, 1974; Milner, 1982), on the other hand, behaves essentially like S. K. It should be noted that some acallosals (e.g. Lassonde et al. 1983) have difficulty in maintaining ocular fixation. However, our patients K.C. and B.F. seem not to, since lateral differences persist, despite the use of very small visual angles (see Lines, 1983, and below). It is possible that both K.C. and S.K. have a dynamically-dominant speech mechanism on one side, which controls all spoken behaviour except in very exceptional circumstances.

The second question concerns the mechanisms of functional compensation in the brain. There are several possibilities, but little evidence to help one choose between them. The first line of evidence concerns the somatosensory system. Several investigators, though not all (e.g. Jeeves, 1979), have found that tactile integration between the hands, although sufficiently good for matching or identifying objects, is relatively impaired where cross-localization of stimulated points on the fingers is required (Gazzaniga, 1970; Ettlinger et al. 1972; Dennis, 1976; Reynolds \& Jeeves, 1977). But Dennis (1976) has shown that an equal impairment is present where no cross-integration is required, but a similar cognitive demand is made. This strongly suggests that tactile localization is intrinsically poor, and Dennis argues that this is a consequence of an overdeveloped ipsilateral sensory pathway, which permits cross-integration (through a single hemisphere) at the cost of reduced sensory acuity. A lower somatosensory acuity is also manifest in a tendency to make errors when asked to report how many fingers apart two stimulated fingers are (Dennis, 1976).

If a sensory projection rather than a commissural one has developed to permit tactile cross- 
integration, the reverse seems likely to be the case in the visual domain. The capacity to name or cross-match lateralized visual stimuli would seem very likely to be mediated by a visual commissure. However, it would be possible in theory for the normal nasotemporal segregation of retinal ganglion cell fibres to be partially lost such that there was some input from each half of the visual field to the ipsilateral visual system. Furthermore, the acallosal subject's ability to make quick 'crossed' visuomotor responses (e.g. left visual field, right index finger) could be due to either of these two possibilities, or a third, namely the use of the ipsilateral motor projection (Kinsbourne \& Fisher, 1971) which in normals is incapable of precise motor control (Brinkman \& Kuypers, 1973). All these possibilities would be compatible with the observation that those acallosal subjects who have been extensively tested have been found to make 'crossed' responses in the visual simple-reaction-time (RT) task about $20 \mathrm{~ms}$ slower than uncrossed responses (Jeeves, 1969; Reynolds \& Jeeves, 1974; Milner et al. 1983). However, certain variations of the task help to eliminate the options. The acallosals K.C. and B.F. have recently been found to maintain their large crossed-uncrossed difference (CUD) at a variety of stimulus eccentricities, even down to $\frac{1}{2}^{\circ}$ (K.C.) and $\frac{1}{4}^{\circ}$ (B.F.) (Lines, 1983; and unpublished). Yet if there were any useful ipsilateral visual projection, it would be expected to be clearly present at these small distances from the vertical meridian of the visual field; in that case the stimulus should no longer be lateralized to the contralateral cerebral hemisphere alone and hence no CUD should be observed.

Both of these acallosals have been tested in the same RT task, using different levels of stimulus luminance. Both have been found to generate clear and statistically reliable increases in CUD at low stimulus levels (Milner, 1982; Milner et al. 1983). These data are difficult to explain in terms of the theory that crossed RTs are mediated by ipsilateral motor pathways, but instead seem to implicate a commissural pathway coded for elementary visual stimulus characteristics. This relationship between stimulus intensity and size of the CUD is not found in normal subjects (Milner $\&$ Lines, 1982) whose brains evidently send a more abstract or response-related message across the corpus callosum in this task. It is also possible to exclude spatial compatibility $v$. incompatibility as a determinant of the acallosal's CUD (cf. Kinsbourne \& Fisher, 1971), since B.F. shows an unchanged CUD, even when the responding arm is maintained in an extreme contralateral location during the task (Milner et al. 1983). On the basis of these various results, it seems most reasonable to implicate either the anterior commissure (or perhaps a midbrain commissure) in crossed visual reactions in acallosal patients, rather than the alternatives of ipsilateral visual or motor transmission.

This brings us to the final question, since although there may be normally no efficient ipsilateral motor control of the fingers, it has been argued (Dennis, 1976) that ipsilateral control nonetheless develops by default in the absence of callosal influence, to the detriment of fine contralateral control. Certainly, synkinesic 'unintended' movements do occur in acallosal patients, and a general clumsiness in skilled movement has often been reported (e.g. Jeeves, 1965; Reynolds \& Jeeves, 1977). Synkinesias also occur in other pathological conditions (Abercrombie et al. 1964; Schott \& Wyke, 1981) where callosal pathology is generally absent, but where it may still be true that normal suppressive or inhibitory processes are not fully functional. An absence of such processes more generally in acallosal brain development would also account for the finger-localization deficiencies described above, if it can be assumed that fine tactual distinctions also require that ipsilateral pathways be suppressed.

Limits on visual cross-integration in callosal agenesis are less clear, but seem likely to exist. In particular, the normal visual input to the primate anterior commissure emphasizes information about pattern at the expense of information about location (Jouandet \& Gazzaniga, 1979; Ungerleider \& Mishkin, 1982). Although the neocortical field of origin of the anterior commissure in the acallosal brain may be less restricted than normal (Bossy, 1970), possibly through the retention of connections otherwise lost during callosal development (Auroux \& Roussel, 1967), it will be interesting to determine whether spatial cross-matching will be impaired, as it is following callosal section (Holtzman et al. 1981). In one acallosal patient location in the right half of the visual field has been found to be poor (Martin, 1981); however, this is not so in our patient B.F. and so may not be generalizable.

Intellect is generally underdeveloped in callosal agenesis, but whether this should be attributed 
to reduced interhemispheric communication or to other brain abnormalities is unknown. The most frequent description is of poor showing on 'performance' tests (e.g. Sperry, 1968), but Dennis (1977) has argued that there is just as likely to be a large difference in favour of Wechsler Performance over Verbal IQ as vice versa, and Chiarello (1980) calculates the average discrepancy to be zero (mean Verbal IQ $=89$, mean Performance IQ $=89$ among the published cases, excluding retardates). Dennis (1981) has reported on a number of linguistic tests given to an acallosal (D.S.) with a lower Verbal than Performance IQ. The most pervasive difficulty for this patient seemed to be in syntactic comprehension, although a word-finding difficulty also emerged in certain tests. In similar tests given to three acallosals (B.F., K.C. and M.J.) we too have found some similar impairments, but in no instance where D.S. was impaired have we found all three of our patients to be impaired (Jeeves et al. 1983). One very marked difficulty for D.S. was in retrieving words in response to rhyming cues; we have found a comparable problem in K.C. and B.F., but not in M.J. (despite his being only 6 years old). Indeed, in most cases M.J. was the least (relatively) impaired of the three, and this probably reflects the fact that he has a positive Verbal-Performance IQ discrepancy while the other two, like D.S., have the reverse. Similarly, Dennis (1977) reported that her partially acallosal J.E., who had a higher Verbal than Performance IQ, performed well on a test of syntactic comprehension. It may be the case that in agenesis 'either a linguistic or a spatial capacity develops' (Dennis, 1977). However, it will not be possible to state with certainty that the pattern of performance found in the 'undeveloped' part of the intellect is abnormal until controls matched not only on overall cognitive level but also on Verbal-Performance IQ discrepancy are examined.

In summary, the following provisional answers may be given to the three questions posed at the beginning of this editorial. First, there is no good evidence that acallosal brains are any less laterally specialized than normal ones; so there is no compelling reason to argue that hemispheric specialization requires the corpus callosum to have been present in childhood. Secondly, there is evidence for the use of visually-coded commissural fibres in some tests of cross-integration, but also of ipsilateral sensory pathways (tactile, and possibly auditory) in others. Finally, it is likely that both cognitive and skilled performances suffer as a result of callosal agenesis; but there are great individual differences and the nature of the impairments remains unclear.

DAVID MILNER

\section{REFERENCES}

Abercrombie, M. L., Lindon, R. L. \& Tyson, M. C. (1964). Associated movements in normal and physically handicapped children. Developmental Medicine and Child Neurology 6, 573-580.

Auroux, M. \& Roussel, C. (1967). Relations néocorticales assurées par la commissure blanche antérieure chez le foetus humain. Comptes Rendus de $\Gamma$ Association des Anatomistes 137, 152-159.

Bossy, J. G. (1970). Morphological study of a case of complete, isolated and asymptomatic agenesis of the corpus callosum. Archives d Anatomie, d Histologie et d' Embryologie 53, 289-340.

Brinkman, J. \& Kuypers, H. G. J. M. (1973). Cerebral control of contralateral and ipsilateral arm, hand and finger movements in the split-brain rhesus monkey. Brain 96, 653-674.

Chiarello, C. (1980). A house divided? Cognitive functioning with callosal agenesis. Brain and Language 11, 128-158.

Denenberg, V. H. (1981). Hemispheric laterality in animals and the effects of early experience. Behavioral and Brain Sciences 4, 1-49.

Dennis, M. (1976). Impaired sensory and motor differentiation with corpus callosum agenesis: a lack of callosal inhibition during ontogeny? Neuropsychologia 14, 455-469.

Dennis, M. (1977). Cerebral dominance in three forms of early brain disorder. In Topics in Child Neurology (ed. M. E. Blaw, I. Rapin and M. Kinsbourne), pp. 189-212. Spectrum: New York.

Dennis, M. (1981). Language in a congenitally acallosal brain. Brain and Language 12, 33-53.

Ettlinger, G., Blakemore, C. B., Milner, A. D. \& Wilson, J. (1972). Agenesis of the corpus callosum : a behavioural investigation. Brain 95, 327-346.
Gazzaniga, M. S. (1970). The Bisected Brain. Appleton-CenturyCrofts: New York.

Gazzaniga, M. S., Bogen, J. E. \& Sperry, R. W. (1965). Observations on visual perception after disconnexion of the cerebral hemispheres in man. Brain 88, 221-236.

Gott, P. S. \& Saul, R. E. (1978). Agenesis of the corpus callosum: limits of functional compensation. Neurology 28, 1272-1279.

Holtzman, J. D., Sidtis, J. J., Volpe, B. T., Wilson, D. H. \& Gazzaniga, M.S. (1981). Dissociation of spatial information for stimulus localization and the control of attention. Brain 104, 861-872.

Jeeves, M. A. (1965). Psychological studies of three cases of congenital agenesis of the corpus callosum. In Functions of the Corpus Callosum (ed. G. Ettlinger), pp. 73-94. Ciba Foundation Study Groups No. 20. Churchill: London.

Jeeves, M. A. (1969). A comparison of interhemispheric transmission times in acallosals and normals. Psychonomic Science 16, 245-246.

Jeeves, M. A. (1979). Some limits to interhemispheric integration in cases of callosal agenesis and partial commissurotomy. In Structure and Function of the Cerebral Commissures (ed. I. S. Russell, M. W. van Hof and G. Berlucchi), pp. 449-474. Macmillan London.

Jeeves, M. A., Milner, A. D. \& Silver, P. H. (1983). Language in callosal agenesis: deficits and asymmetries. Manuscript in preparation.

Jouandet, M. L. \& Gazzaniga, M. S. (1979). Cortical field of origin of the anterior commissure of the rhesus monkey. Experimental Neurology 66, 381-397. 
Kinsbourne, M. \& Fisher, M. (1971). Latency of uncrossed and of crossed reaction in callosal agenesis. Neuropsychologia 9, 471-473.

Kinsbourne, M. \& Hiscock, M. (1977). Does cerebral dominance develop? In Language Development and Neurological Theory (ed. S. J. Segalowitz and F. A. Gruber), pp. 171-191. Academic Press: New York.

Lassonde, M. C., Laurencelle, L. \& Geoffroy, G. (1983). Hemispheric specialization in callosal agenesis: evidence from a tachistoscopic study. Manuscript submitted for publication.

Lines, C. R. (1983). Nasotemporal overlap investigated in a case of agenesis of the corpus callosum. Manuscript submitted for publication

Loeser, J. D. \& Alvord, E. C. Jr (1968a). Agenesis of the corpus callosum. Brain 91, 553-570.

Loeser, J. D. \& Alvord, E. C. Jr (1968b). Clinicopathological correlations in agenesis of the corpus callosum. Neurology 18, 745-756.

McKeever, W. F., Sullivan, K. F., Ferguson, S. M. \& Rayport, M. (1981). Typical cerebral hemisphere disconnection deficits following corpus callosum section despite sparing of the anterior commissure. Neuropsychologia 19, 745-755.

Martin, A. (1981). Visual processing in the acallosal brain: a clue to the differential functions of the anterior commissure and the splenium. Paper presented at the 9th Annual Meeting of the International Neuropsychological Society.

Milner, A. D. (1982). Simple reaction times to lateralized visual stimuli in a case of callosal agenesis. Neuropsychologia 20,411-419.

Milner, A. D. \& Jeeves, M. A. (1979). A review of behavioural studies of agenesis of the corpus callosum. In Structure and Function of the Cerebral Commissures (ed. I. S. Russell, M.W. van Hof and G. Berlucchi), pp. 428-448. Macmillan: London.

Milner, A. D. \& Jeeves, M. A. (1981). Commentary: The functions of the corpus callosum in infancy and adulthood. Behavioral and Brain Sciences 4, 30-31.

Milner, A. D. \& Lines, C. R. (1982). Interhemispheric pathways in simple reaction time to lateralized light flash. Neuropsychologia $\mathbf{2 0}$ 171-179.

Milner, A. D., Lines, C. R., Jeeves, M. A. \& Silver, P. H. (1983),
Reaction times to lateralised visual stimuli in callosal agenesis: stimulus and response factors. Manuscript in preparation.

Moscovitch, M. (1977). Development of lateralization of language functions and its relation to cognitive and linguistic development: a review. In Language Development and Neurological Theory (ed. S. J. Segalowitz and F. Gruber), pp. 193-211. Academic Press: New York.

Rasmussen, T. \& Milner, B. (1977). The role of early left-brain injury in determining lateralization of cerebral speech functions. Annals of the New York Academy of Sciences 299, 355-369.

Reynolds, D. M. \& Jeeves, M. A. (1974). Further studies of crossed and uncrossed pathway responding in callosal agenesis - reply to Kinsbourne and Fisher. Neuropsychologia 12, 287-290.

Reynolds, D. M. \& Jeeves, M. A. (1977). Further studies of tactile perception and motor coordination in agenesis of the corpus callosum. Cortex 13, 257-272.

Risse, G. L., Le Doux, J., Springer, S. P., Wilson, D. H. \& Gazzaniga, M. S. (1978). The anterior commissure in man: functional variation in a multisensory system. Neuropsychologia 16, 23-31.

Schott, G. D. \& Wyke, M. A. (1981). Congenital mirror movements. Journal of Neurology, Neurosurgery and Psychiatry 44, 586-599.

Selnes, O. A. (1974). The corpus callosum: some anatomical and functional considerations with special reference to language. Brain and Language 1, 111-139.

Sperry, R. W. (1968). Plasticity of neural maturation. Developmental Biology Supplement 2, 306-327.

Sperry, R. W. (1974). Lateral specialization in the surgically separated hemispheres. In The Neurosciences Third Study Program (ed. F. O. Schmitt and F. G. Worden), pp. 5-19. MIT Press: Cambridge, Mass.

Ungerleider, L. G. \& Mishkin, M, (1982). Two cortical visual systems. In Analysis of Visual Behavior (ed. D. J. Ingle, M. A Goodale and R. J. W. Mansfield), pp. 549-586. MIT Press: Cambridge, Mass.

Wilson, D. H., Reeves, A. G. \& Gazzaniga, M. S. (1982). 'Central' commissurotomy for intractable generalized epilepsy: series two. Neurology 32, 687-697. 